\title{
PERANCANGAN BRAND IDENTITY KERIPIK WAHYU LUWUK BANGGAI
}

\author{
Fakhrunnisa Djokja, Abdul Azis Said, Nurabdiansyah \\ Desain Komunikasi Visual Fakultas Seni dan Desain Universitas Negeri Makassar \\ fakhrunnisadjokja@gmail.com \\ abd.azis.said@unm.ac.id \\ nurabdiansyah@unm.ac.id
}

\begin{abstract}
ABSTRAK
Perancangan ini bertujuan menciptakan brand identity sebagai pengembangan usaha keripik Wahyu dan memperkenalkan identitas usaha melalui media komunikasi visual agar menjadi perhatian dan meluasnya lingkup konsumen dari keripik Wahyu. Pengumpulan data dilakukan berkaitan dengan proses perancangan mengenai teori visual, warna, font, layout, logo, graphic standard manual, kemasan dan perancangan media komunikasi visual dan produk keripik Wahyu, observasi lapangan, wawancara dan dokumentasi. Data dianalisis dengan metode deskriptif kualitatif dan analisa terhadap kompetitor sejenis sebagai bahan banding dengan menggunakan analisis SWOT untuk mendapatkan positioning dan diferensiasi sebagai pengembangan dari identitas usaha. Konsep dalam perancangan ini menampilkan keripik Wahyu sesuai dengan identitas usahanya yaitu sebuah produk/keripik produksi Luwuk Banggai dengan kesan yang simpel sehingga mudah untuk diingat dan lebih modern, meninggalkan gaya lama dengan pembaharuan yang dapat menjadi perhatian untuk meluasnya lingkup konsumen keripik Wahyu. Hasil perancangan berupa logo yang merupakan penggabungan dari logogram dan logotype yang menjadi satu kesatuan yang dinamis. Logo akan diaplikasikan pada media komunikasi visual. Media utama berupa desain kemasan dan media pendukung lainnya berupa stationary dan media promosi.
\end{abstract}

Kata Kunci: Brand Identity, Keripik Wahyu, Media Komunikasi Visual

\begin{abstract}
This design aims to create a brand identity as a development of Keripik Wahyu business and introduce business identity through visual communication media to attract attention and expand the scope of consumers of Keripik Wahyu. Collecting data related to the design process regarding visual theory, color, font, layout, logo, graphic standard manual, packaging and design of visual communication media and Keripik Wahyu's products, field observations, interviews and documentation. Data were analyzed using descriptive qualitative methods and analysis of similar competitors as a comparison using analysis SWOT to obtain positioning and differentiation as a development of business identity. The concept in this design displays Keripik in accordance with its business identity, namely a product / chip produced by Luwuk Banggai with a simple impression that is easy to remember and more modern, leaving the old style with renewal that can be a concern for the widening scope of Keripik Wahyu's consumers. The design result is in the form of a logo which is a combination of logogram and logotype which becomes a dynamic unit. The logo will be applied to visual communication media. The main media are packaging design and other supporting media in the form of stationary and promotional media.
\end{abstract}

Keywords: Brand Identity, Keripik Wahyu, Visual Communication Media

\section{PENDAHULUAN}

Kabupaten Banggai merupakan salah satu Kabupaten di Sulawesi Tengah yang memiliki potensi sumber daya alam yang melimpah, baik berupa hasil laut dan aneka hasil bumi (kopra, sawit, coklat, beras, kacang mente dan lainnya) termasuk juga 
pada jenis tanaman umbi-umbian, seperti ubi jalar, singkong dan salah satunya adalah bahan lokal umbi keladi atau talas (Djamal, 2014).

Umbi keladi (talas) dapat dikategorikan sebagai usaha tani keluarga dan biasanya hanya dibiarkan tumbuh begitu saja karena keladi (talas) di Kabupaten Banggai tidak menjadi makanan pokok prioritas utama. Oleh sebab itu dilakukan sebuah upaya dalam memenuhi kebutuhan pangan adalah dengan meningkatkan produktivitas budidaya pangan melalui pemanfaatan teknologi sehingga perlu adanya pemanfaatan dalam pengolahan keladi menjadi produk olahan baru yang memiliki keuntungan yaitu dengan mengolahnya menjadi keripik. Sehingga cukup banyak warga Luwuk yang memanfaatkan potensi tersebut untuk dijadikan sebuah wirausaha yang juga menciptakan banyak oleh-oleh khas Luwuk Banggai.

Oleh-oleh atau buah tangan bukan semata hadiah dan kenang-kenangan dari seseorang yang baru saja kembali dari suatu daerah atau negara. Lebih dari itu, bingkisan tersebut bisa menjadi senjata untuk mendorong promosi lokal. "Kuliner khas suatu negara memang penting, namun barang yang dibawa seseorang bisa menyebarkan lebih luas. Kalau tidak ada buah tangan, bagaimana mau berbagi pengalaman dari suatu daerah?" kata Vita Datau, ketua tim percepatan kuliner dan belanja Kementerian Pariwisata, saat ditemui $C N N$ Indonesia di kawasan Dharmawangsa, Jakarta Selatan.

Trend wisatawan sekarang adalah datang ke suatu daerah wisata untuk mencari atau berburu makanan khas daerah tersebut dan tidak segan-segan membayar mahal untuk menikmati suatu hidangan. Perubahan gaya hidup masyarakat juga telah terjadi, mereka makan tidak hanya untuk mengenyangkan perut saja, tetapi juga mencari suasana dan pelayanan sebagai bagian dari sajian makanan yang dipesan.

Menurut Yongky Safanayong (2006:62), Desain Kemasan adalah alat pemasaran yang terpenting untuk barang-barang yang dikemas. Kemasan mengkomunikasikan brand dan nilai produk pada point of sale. Desain stuktur kemasan atau wajah grafis mampu membedakan suatu produk dari pesaingnya".

Brand merupakan ekuitas perusahaan yang menambah value (nilai) bagi produk dan jasa yang ditawarkan. Merek merupakan aset yang menciptakan value bagi pelanggan dengan memperkuat kepuasan dan pengakuan atas kualitas. (Kartajaya, 2004). Sehingga sebuah brand yang akan dibangun nantinya menghasilkan nilai-nilai dari usaha tersebut. Nilai-nilai tersebut yang akan menjadi sebuh pembeda dan dapat menempatkan usaha tersebut lebih unggul dari pada kompetitornya.

Sementara itu usaha keripik Wahyu yang menjadi salah satu rekomendasi oleholeh ketika berkunjung di Luwuk Banggai, selama berkembangnya usaha keripik Wahyu ini belum memiliki logo usaha, hanya memakai name tag saja yang tidak menggambarkan identitas dari usaha ini.

Selain itu kemasan dari keripik Wahyu ini terlihat kurang menarik dan tidak ada perubahan tampilannya dari awal produksi, sedangkan desain kemasan merupakan salah satu yang terpenting dalam pemasaran produk yang dikemas, seperti yang dijelaskan di atas, dan menjadi sebuah pembeda antara usaha sejenisnya. Pemasaran dari keripik Wahyu juga belum tersebar luas, sehingga diperlukan sebuah proses kreatif demi lebih berkembangnya usaha ini agar dikenal oleh masyarakat luas atau meluasnya pemasaran dari usaha keripik Wahyu.

Oleh karena itu perlu dilakukan sebuah pengembangan brand identity yang lebih akrab dikenal dengan sebutan merek/logo dan meningkatkan media pemasaran yang telah ada agar informatif dan menarik sehingga meningkat pula kepercayaan dan meluasnya lingkup konsumen dari Keripik Wahyu. 


\section{METODE}

Dalam perancangan brand identity dilakukan pengumpulan data untuk memperoleh informasi yang dibutuhkan secara deskriptif sesuai dengan apa yang ada di lapangan. Beberapa teknik/metode pengumpulan data yang dilakukan:

\subsection{Teknik Pengumpulan Data}

a. Penelusuran/Kajian Kepustakaan

Kajian pustaka dilakukan untuk memperoleh data-data yang berkaitan dalam proses perancangan brand identity mengenai teori-teori visual, warna, font, layout, logo, graphic standards manual, kemasan, perancangan media komunikasi visual dan produk keripik Wahyu.

b. Observasi Lapangan

Pengumpulan data yang dilakukan secara langsung di tempat produksi Keripik Wahyu di jalan Kenanga No.133 Kelurahan Hanga-hanga, Kecamatan Luwuk Selatan, Kabupaten Banggai, dengan mengamati tampilan produk dan media apa saja yang telah dipakai sebelumnya, juga mengetahui bagaimana cita rasa dan varian dari keripik Wahyu, dan melakukan pengamatan terhadap kompetitor usaha sejenis dan mencari tahu diferensiasinya di beberapa swalayan dan pusat oleh-oleh yang ada di Luwuk Banggai dan promosi seperti apa yang telah dilakukan untuk mengembangkan usaha dari Keripik Wahyu itu sendiri.

\section{c. Interview/wawancara}

Melakukan wawancara dengan pemilik usaha Keripik Wahyu bapak Toto Rahardjo guna mendapatkan data tentang identifikasi produk dan data yang berkaitan dengan usaha tersebut, antara lain: bagaimana perjalanan bisnis usaha tersebut, pemilihan nama usahanya, harapan dari pelaku usaha demi kemajuan usaha untuk kedepannya, siapa yang menjadi target audiens sasarannya, keistimewaan yang ditawarkan oleh produk ini dan juga pemahaman pelaku usaha tentang pentingnya sebuah brand dimiliki oleh sebuah usaha juga media komunikasi visual yang merupakan hal penting dalam strategi pemasaran sebuah produk. Metode ini dilakukan untuk mendapatkan bukti yang sesungguhnya dari sumber yang terkait.

d. Dokumentasi

Metode ini dilakukan guna memperoleh data visual diambil melalui kamera antara lain: berupa hasil pengamatan yang telah dilakukan, dan foto produk yang kemudian dijadikan acuan dalam mendesain.

\subsection{Teknik Analisis Data}

Dalam proses menganalisis data dilakukan dengan menggunakan teknik deskriptif kualitatif. Metode ini digunakan untuk mengelolaan data kepustakaan, observasi dan wawancara. Medote analisis SWOT, terdiri dari strength yaitu dengan melihat apa saja yang menjadi keunggulan produk yang menjadi kompetitor dibandingakan dengan apa yang dimiliki dari produk yang dipilih, weakness yaitu dengan melihat kekurangan apa saja yang ditemukan pada produk kompetitor, opportunities yaitu dengan melihat kesempatan produk yang dipilih dibandingkan dengan produk kompetitor, threat yaitu dengan melihat apa saya yang sudah ada pada produk kompetitor terhadap produk yang dipilih.

\section{HASIL DAN PEMBAHASAN}

\subsection{Konsep Desain}

Konsep desain yang digunakan dalam perancangan brand identity keripik Wahyu Luwuk Banggai adalah simple dan modern. Simple berarti sederhana, tidak memiliki ornamen yang berlebihan. Sedangkan modern berarti pembaruan atau meninggalkan gaya atau trend lama. Visual brand identity akan menampilkan secara visual bahwa Wahyu merupakan sebuah 
produk (keripik) produksi Luwuk Banggai. Oleh karena itu digunakan visual bentuk keripik sebagai produk apa yang dijual dan icon Luwuk Banggai yaitu burung Maleo untuk menandakan produksi Luwuk Banggai.

Visual identity yang akan dibangun menampilkan kesan sederhana dan kebaruan. Ilustrasi keripik dan burung Maleo yang akan menggambarkan identitas usaha keripik Wahyu, dengan menyederhanakan bentuk yang sudah ada sesuai dengan konsep desain yaitu simpel. Elemen estetis yang digunakan dalam perancangan kemasan sebagai media utama dibuat lebih modern dibandingkan dengan kemasan produk sebelumnya.

\subsection{Sumber Inspirasi}

Sumber inspirasi dalam perancangan ini yaitu bentuk keripik dan burung Maleo.

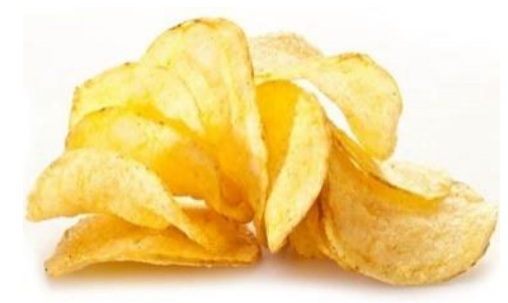

Gambar 3.1 Keripik (Sumber Internet)

Bentuk keripik yakni menyerupai lingkaran atau oval dan melengkung.

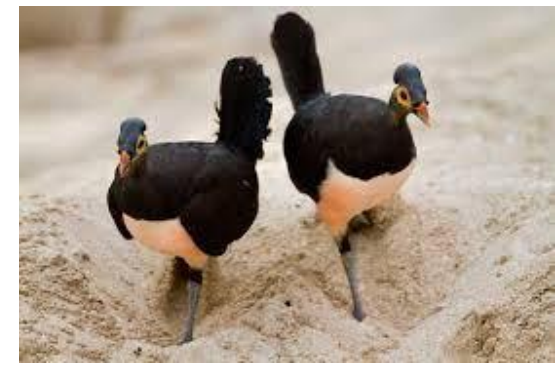

Gambar 3.2 Burung Maleo (Sumber Internet)

Bentuk kepala burung Maleo dengan tonjolan yang cukup besar yang berada dibagaian atas belakang kepalanya.

\subsection{Tipografi}

Menurut hasil analisis data selain menggunakan teknik handlettering, beberapa jenis font yang akan digunakan dalam perancangan ini antara lain sebagai berikut:

\section{1) Source Sans Pro ABCDEFGHIJKLMNOPQRSTUVWXYZ abcdefghijklmnopqrsturwxyz}

Karakter yang dimiliki oleh font ini adalah karakter yang tegas, modern, mudah terbaca dan memiliki ketebalan huruf yang sama. Tergolong dalam tipe sans. Bisa diaplikasiakan pada heading/judul amaupun bodytext/isi.

\section{2) Hildany $\triangle B C D E F G H \| K L M N O P Q R S T U V W X Y Z$ abcdefghijklmnopgrsturwxyz}

Karakter yang dimiliki oleh font ini adalah karakter yang santai, mudah terbaca, akan diaplikasikan pada nama produk ataupun bodytext/isi.

\subsection{Warna}
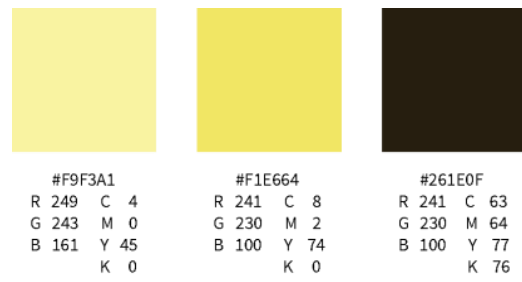

\#261EOF

$\begin{array}{lll}241 & C & 63 \\ 230 & \text { M } & 64\end{array}$

$\begin{array}{llll}\text { G } 230 & \text { M } & 64 \\ \text { B } 100 & \text { Y } & 77 \\ & & \text { K } & 76\end{array}$

Warna Utama yang akan diterapkan pada logo

Warna kuning memenggambarkan keceriaan dan kebaruan kesan keceriaan mendukung membangkitkan mood kostumer dan kebaruan menandakan bahwa Wahyu akan terus mengembangkan bisnis usahanya dengan inovasi baru dari produk yang dijual.

Warna coklat melambangkan kesederhanaan, kewibawaan dan kedewasaan dari usaha keripik Wahyu yang sudah dirintis dari tahun 1990an. 


\subsection{Sketsa}

Berikut adalah visualisasi dari sumber inspirasi keripik Wahyu yang sudah dijabarkan sebelumnya.
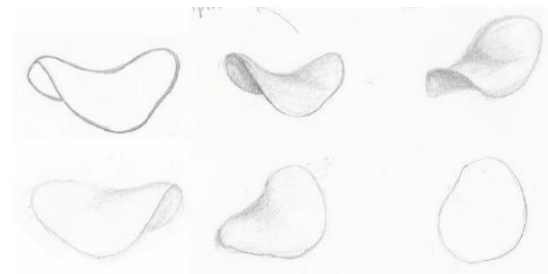

Gambar 3.3 Sketsa Bentuk Keripik (Sumber: Fakhrunnisa, 2019)

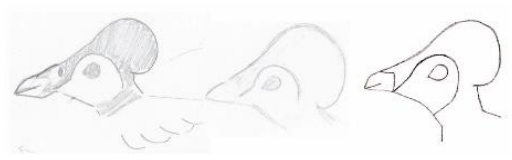

Gambar 3.4 Sketsa Kepala Burung Maleo (Sumber: Fakhrunnisa, 2019)
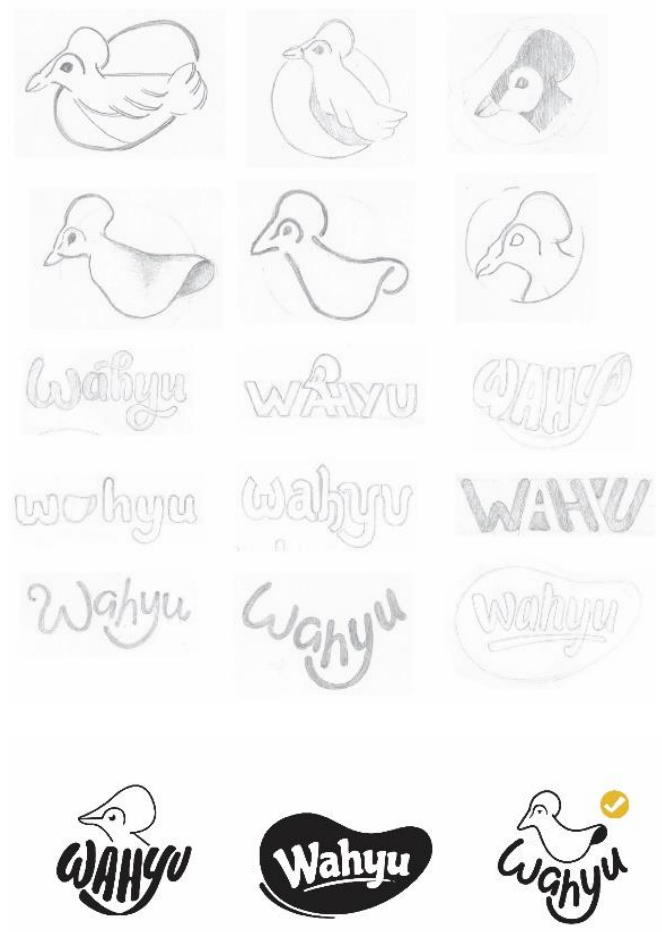

\section{WAHYU}

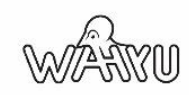

WAHY

Gambar 3.5 Eksplorasi Logo Wahyu (Sumber: Fakhrunnisa Djokja)

\subsection{Implementasi Digital}

Dari sketsa yang terpilih sebelumnya dilakukan proses digitalisasi logogram dan logotype dengan perangkat desain yang digunakan. Tahap digitalisasi dilakukan dengan menggunakann program desain Adobe Illustrator CS6.

Digitalisasai logo keripik Wahyu dibuat dengan membuat line art mengikuti sketsa logo dan juga menggunakan grid system. kemudian dilanjutkan dengan pewarnaan logo sesuai dengan warna yang telah ditentukan.

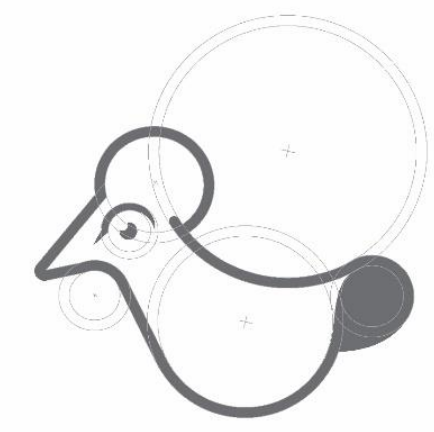

Gambar 3.6 Konstruksi Logogram (Sumber: Fakrunnisa Djokja)

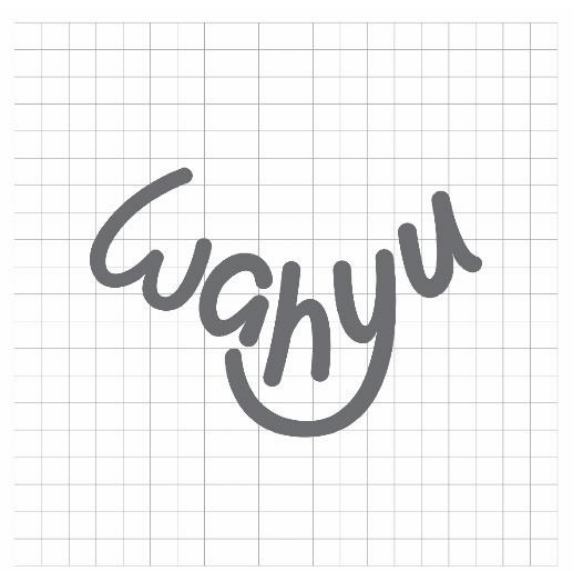

Gambar 3.7 Grid Logotype

(Sumber: Fakhrunnisa, 2019) 


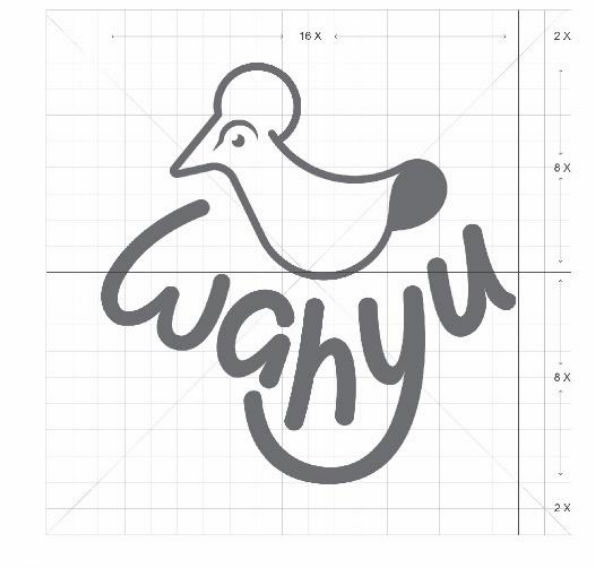

Gambar 3.8 Grid Logogram dan Logotype (Sumber: Fakhrunnisa, 2019)

\subsection{Hasil Perancangan}

Hasil dalam perancangan brand identity ini berupa logo, merupakan penggabungan logogram dan logotype yang dinamis dengan tampilan yang simple namun tetap mencerminkan identitas usaha. Logogram menyampaikan pesan visual yang terinspirasi dari bentuk keripik dan ikon Luwuk Banggai sebagai representative dari identitas usaha Wahyu dan didukung oleh logotype yang menjelaskan nama usaha yaitu Wahyu.

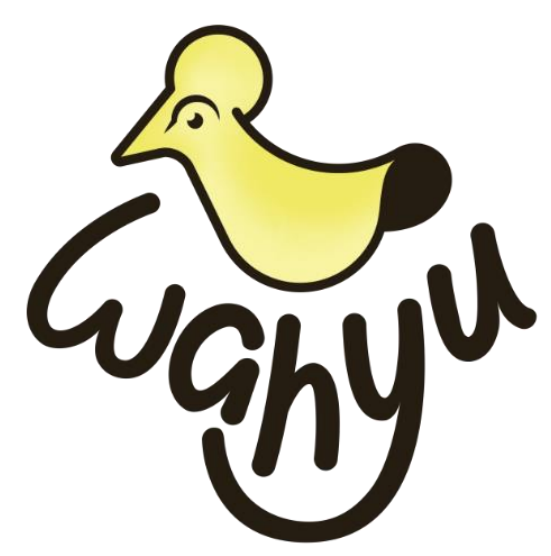

Gambar 3.9 Final Logo Keripik Wahyu (Sumber: Fakhrunnisa,2019)

\section{a. Media Utama}

Kemasan yang digunakan adalah standing pouch zipper. Bahan dari paper metal/alumuniumfoil dengan laminasi matte, ukuran $16 \times 25,5 \mathrm{~cm}$. Pada bagian belakang kemasan memiliki daerah transparant yang memperlihatkan isi produk. Pemilihan warna pada kemasan disesuaikan dengan bahan olahan keripik tersebut sesuai dengan varian keripik yang ada.

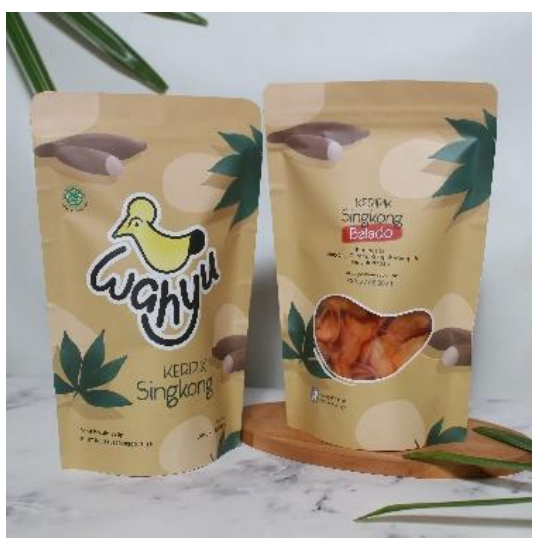

Gambar 3.10 Tampak Depan dan Belakang Mockup Desain Kemasan Keripik Wahyu

(Sumber: Fakhrunnisa, 2020)

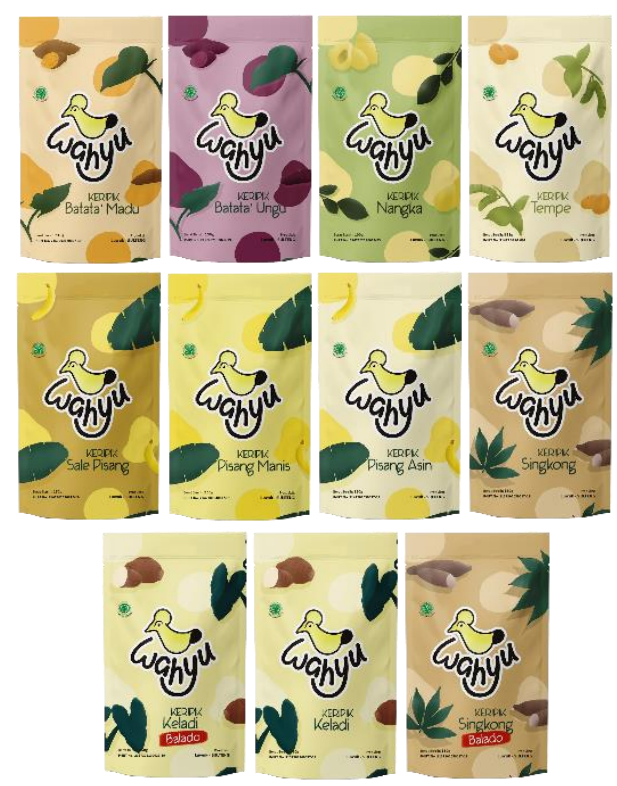

Gambar 3.11 Mockup Kemasan Keripik Wahyu

(Sumber: Fakhrunnisa, 2020) 
b. Media Pendukung

1) Goodie Bag/ Tas Belanja

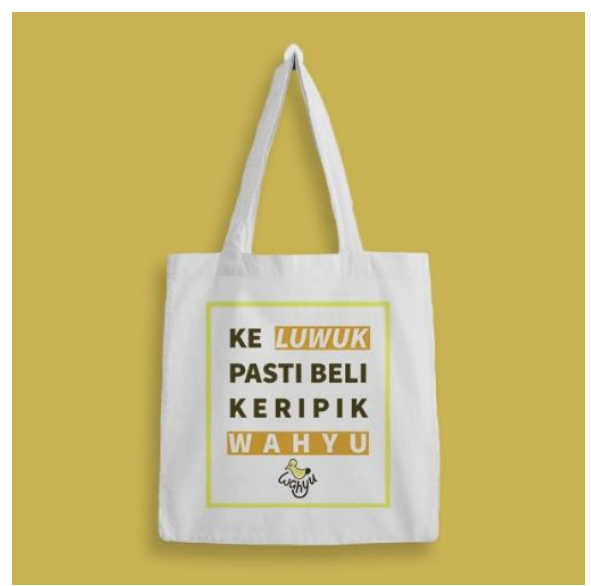

Gambar 3.12 Mockup Goodie Bag

(Sumber: Fakhrunnisa, 2020)

- Bahan : Kanvas

- Ukuran : $30 \times 9 \times 31 \mathrm{~cm}$

- Teknik Cetak : Sablon

2) Kartu Nama

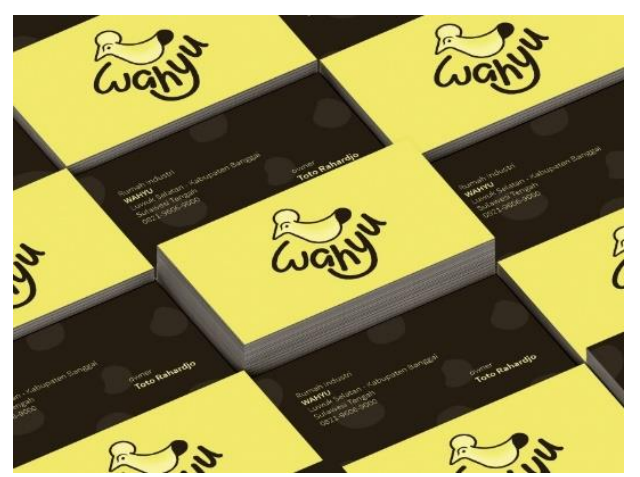

Gambar 3.13 Mockup Kartu Nama

(Sumber: Fakhrunnisa, 2020)

- Bahan : Art Paper

- Ketebalan :260gsm

- Ukuran : 9 x 5,5 cm

- Teknik Cetak : Digital Printing
3) Nota

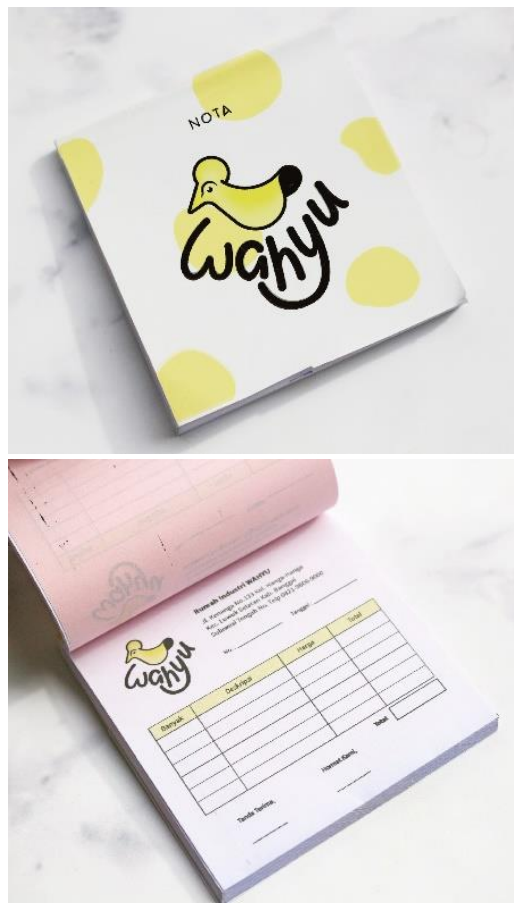

Gambar 3.14 Mockup Nota (Sumber: Fakhrunnisa, 2020)

- Bahan : Kertas NCR

- Ketebalan : $1 \mathrm{~cm}$

- Ukuran $\quad: 10 \times 10.5 \mathrm{~cm}$

- Teknik Cetak : Digital Printing

4) Stempel

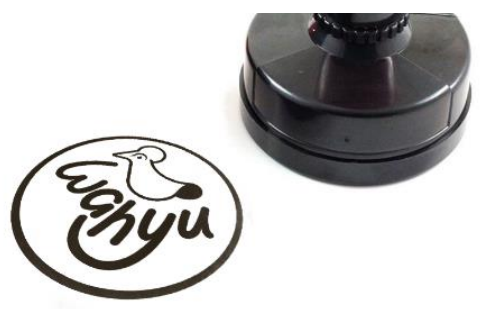

Gambar 3.15 Mockup Stempel (Sumber: Fakhrunnisa, 2020)

- Bahan : Stempel Flash

- Ukuran : $3 \times 3 \mathrm{~cm}$

- Warna Tinta : Coklat 
5) Stiker
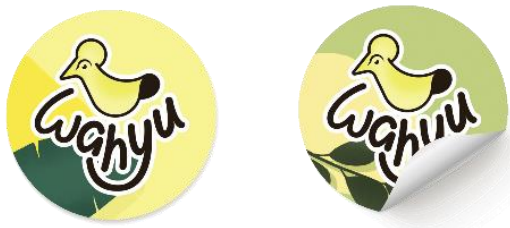

Gambar 3.16 Mockup Stiker

(Sumber: Fakhrunnisa, 2020)

$\begin{array}{lll}\text { - } & \text { Bahan } & \text { : Kertas Stiker } \\ & & \text { Vinyl } \\ \text { - } & \text { Ukuran } & : 5 \mathrm{~cm} \\ \text { - } & \text { Teknik Cetak } & \text { : Digital Printing }\end{array}$

6) Banner

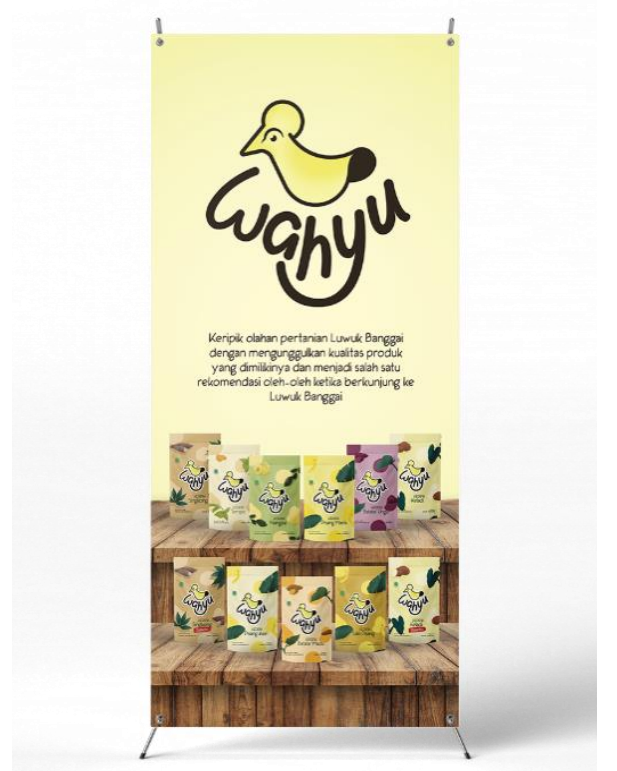

Gambar 3.17 Mockup x-banner

(Sumber: Fakhrunnisa, 2020)

$$
\begin{array}{lll}
\text { - } & \text { Bahan } & \text { : Albatros } \\
\text { - } & \text { Ketebalan } & : 180-210 \mathrm{gsm} \\
\text { - } & \text { Ukuran } & : 60 \times 160 \mathrm{~cm} \\
\text { - } & \text { Teknik Cetak } & \text { : Digital Printing }
\end{array}
$$

\subsection{Pembahasan Hasil Perancangan}

Perancangan ini bertujuan untuk menciptakan visual brand identity berupa logo sebagai pengembangan dari usaha keripik Wahyu. Konsep dari pengembangan logo yang ingin ditampilkan secara visual bahwa Wahyu merupakan sebuah produk/keripik produksi Luwuk Banggai dengan kesan simple. Logo dikategorikan menjadi logogram dan logotype. Logogram menampilkan visual bentuk keripik (sebagai produk apa yg dijual) dan kepala burung maleo (ikon Luwuk Banggai untuk menandakan produksi Luwuk Banggai. Logotype menampilkan nama dari produk dengan menggunakan teknik handlettring mengikuti bentuk logogram sehingga tampak dinamis.

Perancangan logo akan diaplikasikan pada media komunikasi visual. Media utama dalam merancangan ini yaitu desain kemasan dan media pendukung lainnya terdiri dari kartu nama, nota, stempel, goodiebag/tas belanja, stiker dan $x$-banner.

Desain kemasan memiliki super grafis yang berbeda disesuaikan dengan jenis/varian produknya. Tampak depan kemasan mencantumkan informasi tentang logo Wahyu, nama produk, logo halal, netto/berat bersih, nomor pendaftaran dan kode produksi dan alamat produsen. Sedangkan, tampak belakang kemasan mencantumkaan nama produk, komposisi bahan, masa kadaluwarsa dan simbol buang sampah pada tempat. Standing pouch dengan zipper menjadi pilihan karena tergolong dalam kemasan yang fleksibel yaitu dengan harga yang terjangkau, bisa dibuka tutup dan teratur untuk dipajang. Standing pouch tampak lebih modern, kokoh/tidak mudah robek, tahan air dan udara, higienis dan tentunya aman buat makanan.

Media pendukung seperti kartu nama, nota, dan stempel digolongkan dalam stationay pada perancangan ini. Kartu nama menjadi tanda pengenal perusahaan yang berisikan tentang informasi terkait usaha keripik Wahyu antara lain: nama usaha, kontak, alamat dan nama pemilik 
usaha. Kartu nama menggunakan bahan artpaper dengan ukuran $9 \times 5.5 \mathrm{~cm}$. Nota menjadi bukti transaksi atau tanda terima penjualan produk dan menggunakan bahan kertas NCR dengan ukuran $10 \times 10.5 \mathrm{~cm}$. Stempel menjadi tanda bukti penjualan produk yang resmi sehingga terhindar dari kesalapahaman antara penjual dan pembeli. Stempel yang digunakan yakni stempel flash dengan ganggang yang menyimpan tinta dalam karetnya, sehingga lebih praktis.

Sementara goodiebag atau tas belanja, stiker dan x-banner digolongkan dalam material promosi dalam perancangan ini. Desain goodiebag atau tas belanja berupa tipografi yang bertuliskan kata persuasif yaitu mengajak untuk membeli produk dari usaha Wahyu, "KE LUWUK PASTI BELI KERIPIK WAHYU". Tas belanja menggunakan bahan kanvas agar tidak mudah robek dan bisa dicuci sehingga dapat dipakai berulang kali dengan ukuran $30 \times 9 \times 31 \mathrm{~cm}$. Tampilan stiker berupa logo dipadukan dengan supergrafis dari berbagai jenis/varian keripik Wahyu dengan ukuran $5 \mathrm{~cm}$. Sedangkan x-banner berisikan informasi tentang usaha keripik Wahyu dengan menggunakan bahan albatross ukuran $60 \times 160 \mathrm{~cm}$.

\section{KESIMPULAN DAN SARAN 4.1 Kesimpulan}

Telah dihasilkan brand identity berupa logo sebagai pengembangan dari usaha keripik Wahyu, logo merupakan penggabungan logogram dan logotype yang dinamis dengan tampilan yang simple namun tetap mencerminkan identitas usaha. Selain itu, logogram menampilkan secara visual bentuk keripik yang menandakan produk apa yang dijual dan burung maleo sebagai ikon Luwuk Banggai menandakan bahwa produk merupakan produksi Luwuk Banggai dan didukung oleh logotype yang menjelaskan nama usaha yaitu Wahyu.

Logo diaplikasikan pada media komunikasi visual berupa media utama yaitu packaging/kemasan dan media pendukung lainnya seperti kartu nama, nota, stempel, stiker, goodiebag/tas belanja dan $x$-banner.

Selain itu juga dihasilkan desain packaging/kemasan dengan tampilan yang baru menggunakan supergrafis bentuk dari daun dan bahan keripik sesuai dengan jenis keripik yang dijual, warna desain kemasan juga disesuaikan dengan bahan olahan keripik. Packaging/kemasan standing pouch dengan zipper menjadi pilihan karena mudah untuk display, terlihat rapi, modern dan tidak menyusahkan ketika berada ditangan konsumen.

\subsection{Saran}

Perancangan brand identity keripik Wahyu ini tentunya masih memiliki kekurangan karena keterbatasan penulis dan perlu untuk dikembangkan. Adapun saran dari hasil perancangan ini untuk penelitian selanjutnya yaitu:

1. Perancangan selanjutnya sebaiknya memperhatikan bahan dan biaya produksi dari perancangan yang akan dibuat sehingga fungsi rancangan bisa terlaksanakan dengan baik.

2. Pentingnya mengatur atau manage waktu dengan baik ketika membuat karya perancangan.

3. Memperluas wawasan tentang brand atau merek dan data yang dibutuhkan dalam perancangan sehingga dapat lebih berkembanganya alternatif desain dalam sebuah perancangan.

\section{DAFTAR PUSTAKA}

Arsyad, A. (2002). Media Pembelajaran. Jakarta: Raja Grafindo Persada. 
Dewanti, R. (2009). Consumer Perception Analysis Towards Brand Image Hema Dutch Resto. Jakarta Barat: Bina Nusantara University.

Djamal, Z. S. (2014). Analisis Nilai Tambah Keripik Keladi pada Industri Wahyu di Kecamatan Luwuk Selatan Kabupaten Banggai. Skripsi. Palu: Fakultas Pertanian Universitas Tadulako Palu.

Kartajaya, H. (2004). Memenangkan Pesaing dengan Segitiga Positioning-DiferensiasiBrand. Jakarta: Gramedia Pustaka Utama.

Kotler, P., \& Keller, K. L. (2012). Marketing Management. New Jersey: Prentice Hall.

Ladjamudin. (2005). Analisis dan Desain Sistem Informasi. Yogyakarta: Graha Ilmu.

Priherdityo, Endro.(2016, Desember 15). Oleh-oleh Bisa Jadi Senjata Promosi Indonesia.

Di akses pada 5 Desember 2018, dari $C N N$ Indonesia:

https://www.cnnindonesia.com/gaya-hidup/

Rustan, S. (2009). Mendesain Logo. Jakarta: Gramedia Pustaka Utama.

Safanayong, Y. (2006). Desain Komunikasi Visual Terpadu. Jakarta Barat: Arte Intermedia.

Simamora. (2001). Memenangkan Pasan dengan Pemasaran Efektif dan Profitabel. Jakarta: Gramedia Pustaka Utama.

Supriyadi, Fristin, Y., \& Ginanjar, I. (2006). Pengaruh Kualitas Produk dan Brand Image Terhadap Keputusan Pembelian. Jurnal Bisnis dan Manajemen, 3(1):137-138.

Wheeler, A. (2009). Designing Brand Identity:A Complete Guide to Creating, Building, and Maintaining Strong Brands. New Jersey: John Wiley \& Sons, Inc.
Wijaya, R. S., \& Kartika, J. D. (2015). Logo: Visual Asset Development. Indonesia: Elex Media Komputindo. 